\title{
Cellular Mechanisms Mediating Rat Renal Microvascular Constriction by Angiotensin II
}

\author{
Tsuneo Takenaka, ${ }^{\star}$ Hiromichi Suzuki, ${ }^{\ddagger}$ Keiji Fujiwara, ${ }^{\S}$ Yoshihiko Kanno, ${ }^{\S}$ Yoichi Ohno, ${ }^{\S}$ Koichi Hayashi, \\ Takahiko Nagahama, ${ }^{\S}$ and Takao Saruta ${ }^{\S}$ \\ *Shinjuku Suimei Clinic, Shinjuku, Tokyo, 160, Japan; ${ }^{\ddagger}$ Department of Medicine, Saitama Medical College, Iruma, Saitama, 340-03, \\ Japan; and ${ }^{\S}$ Department of Medicine, School of Medicine, Keio University, Shinjuku, Tokyo, 160, Japan
}

\begin{abstract}
To assess cellular mechanisms mediating afferent (AA) and efferent arteriolar (EA) constriction by angiotensin II (AngII), experiments were performed using isolated perfused hydronephrotic kidneys. In the first series of studies, AngII $(0.3 \mathrm{nM})$ constricted AAs and EAs by $29 \pm 3(n=8, P<$ $0.01)$ and $27 \pm 3 \%(n=8, P<0.01)$, respectively. Subsequent addition of nifedipine restored AA but not EA diameter. Manganese $(8 \mathrm{mM})$ reversed EA constriction by $65 \pm 9 \%$ $(P<0.01)$. In the second group, the addition of $N$-ethylmaleimide $(10 \mu \mathrm{M})$, a Gi/Go protein antagonist, abolished AngIIinduced EA $(n=6)$ but not AA constriction $(n=6)$. In the third series of experiments, treatment with 2-nitro-4-carboxyphenyl- $N, N$-diphenyl-carbamate $(200 \mu \mathrm{M})$, a phospholipase $\mathrm{C}$ inhibitor, blocked both AA and EA constriction by AngII ( $n=6$ for each). In the fourth group, thapsigargin (1 $\mu \mathrm{M})$ prevented AngII-induced AA constriction $(n=8)$ and attenuated EA constriction ( $8 \pm 2 \%$ decrease in EA diameter at $0.3 \mathrm{nM}$ AngII, $n=8, P<0.05)$. Subsequent addition of manganese $(8 \mathrm{mM})$ reversed EA constriction. Our data provide evidence that in AAs, AngII stimulates phospholipase $\mathrm{C}$ with subsequent calcium mobilization that is required to activate voltage-dependent calcium channels. Our results suggest that AngII constricts EAs by activating phospholipase $\mathrm{C}$ via the Gi protein family, thereby eliciting both calcium mobilization and calcium entry. (J. Clin. Invest. 1997. 100:2107-2114.) Key words: glomerular arteriole • GTP-binding protein • phospholipase $\mathrm{C} \cdot$ calcium mobilization $\cdot$ calcium entry
\end{abstract}

\section{Introduction}

Several lines of evidence indicate that angiotensin II (AngII) ${ }^{1}$ is a potent renal vasoconstrictor. In addition to its physiologi-

Part of the data in this manuscript was presented at the 29th Annual Meeting of the American Society of Nephrology in New Orleans, LA, November 1996, and has been published in abstract form (1996. $J$. Am. Soc. Nephrol. 7:1581).

Address correspondence to Takao Saruta, M.D., Professor of Medicine, Nephrology Section, Department of Internal Medicine, School of Medicine, Keio University, 35 Shinanomachi, Shinjuku, Tokyo 160, Japan. Phone: 81-3-3353-1211 ext. 2312; FAX: 81-3-33592745.

Received for publication 21 February 1997 and accepted in revised form 23 August 1997.

J. Clin. Invest.

(C) The American Society for Clinical Investigation, Inc. 0021-9738/97/10/2107/08 \$2.00

Volume 100, Number 8, October 1997, 2107-2114

http://www.jci.org cal actions on glomerular hemodynamics and excretory function (1), AngII has been shown to play an important role in mediating pathophysiological renal vasoconstriction in a wide array of disorders, including heart failure, hypertension, and progressive renal diseases (2). Thus, previous studies have demonstrated that angiotensin-converting enzyme inhibition induces beneficial effects on renal functions under the conditions mentioned above (3-6).

On the basis of the above considerations, the elucidation of the mechanisms whereby AngII induces renal vasoconstriction would be of great interest and could provide a theoretical framework for developing strategies for the management of diverse renal diseases. Recent investigations (7-9) have demonstrated that AngII constricts renal microvasculature, including afferent and efferent arterioles. We and other investigators have provided evidence that AngII constricts afferent arterioles by opening chloride channels, thereby inducing membrane depolarization and activation of voltage-dependent calcium channels $(10,11)$. However, the data concerning mechanisms mediating efferent arteriolar constriction by AngII were limited and controversial $(12,13)$. In addition, previous results indicate the absence of voltage-dependent calcium channels on the efferent arteriole (14). Furthermore, recent studies have revealed that AngII opens receptor-operated voltage-independent calcium-permeable cation channels on vascular smooth muscle cells (15), but the relative contribution of these channels to AngII-induced efferent arteriolar constriction has not been fully examined.

To address the controversies, and to assess the calcium activation mechanisms by AngII, we initially assessed the effects of nifedipine, an organic calcium entry blocker, and manganese, a potent inorganic calcium entry blocker possessing the lowest permeability through receptor-operated calcium-permeable cation channels among inorganic calcium blockers (16), on afferent and efferent arteriolar responses to AngII, using an isolated perfused hydronephrotic kidney model in which AngII elicits renal hemodynamic responses similar to those of the normal kidney $(8,17)$. Furthermore, the influence of $N$-ethylmaleimide, a GTP-binding (G) protein antagonist that inhibits the Gi protein family (18), or of thapsigargin, an endoplasmic reticulum calcium pump inhibitor (19), on renal microvascular constriction by AngII was examined. Our results suggest that in afferent arterioles, AngII elicits intracellular calcium mobilization, possibly through Gq proteins, that is required to recruit voltage-dependent calcium channels. Furthermore, these results constitute evidence that AngII-induced efferent arteriolar constriction is mediated by both calcium mo-

1. Abbreviations used in this paper: AngII, angiotensin II; G protein, GTP-binding protein; NCDC, 2-nitro-4-carboxyphenyl- $N, N$-diphenyl-carbamate; NEM, $N$-ethylmaleimide; NS, not significant; TGF, tubuloglomerular feedback. 
bilization and calcium entry via mechanisms dependent on the Gi protein family.

\section{Methods}

AngII, manganese, aluminum chloride $\left(\mathrm{AlCl}_{3}\right), N$-ethylmaleimide (NEM), 2-nitro-4-carboxyphenyl- $N, N$-diphenyl-carbamate (NCDC), sodium fluoride $(\mathrm{NaF})$, and EGTA were obtained from Sigma Chemical Co. (St. Louis, MO). Thapsigargin and staurosporine were obtained from Research Biochemicals Inc. (Natick, MA). Nifedipine was kindly provided by Bayer Co. Ltd. (Osaka, Japan).

43 adult male Sprague-Dawley rats (Charles River Japan, Atsugi, Kanagawa, Japan) were used for the induction of hydronephrosis. The right ureter was exposed by a small abdominal incision and ligated under ether anesthesia (Showa Chemicals, Tokyo, Japan). 8-10 wk after the surgery, renal tubular atrophy had progressed to a stage that allowed direct microscopic visualization of renal microvessels (20). At this point, the kidneys were excised and studied.

For the perfusion of the kidneys, the rats were again anesthetized with ether. The right renal artery was cannulated by introducing the perfusion cannula through the mesenteric artery and across the aorta. Perfusion with warm, oxygenated media $(\mathrm{pH} 7.4)$ was initiated during this cannulation procedure. The kidney was excised, and the renal capsule was removed to promote the visualization of microvessels. The kidney was then placed on the stage of an inverted microscope (model T041; Olympus Corp., Lake Success, NY) modified to accommodate a heated chamber equipped with a thin siliconized glass viewing port on the bottom surface (21).

The perfusion media consisted of Krebs-Ringer bicarbonate buffer containing $5 \mathrm{mM}$ D-glucose and a complement of amino acids, as detailed previously (22). Perfusate was provided to the kidney at a constant pressure from a pressurized chamber. The chamber pressure was maintained by an inflow of warm, hydrated gas of $95 \% \mathrm{O}_{2} / 5 \%$ $\mathrm{CO}_{2}$, which exited through an adjustable back-pressure regulator (model 10BP; Fairchild Industrial Products Co., Winston-Salem, NC). Perfusion pressure was measured at the level of the renal artery and maintained constant at $80 \mathrm{mmHg}$ throughout the experiments. The effluent was returned to the pressurized chamber by two rolling pumps (model 70 16-20; Cole-Parmer Instrument Co., Chicago, IL).

Kidneys were allowed to equilibrate for at least $30 \mathrm{~min}$ before basal measurements were obtained, and experimental manipulations were then initiated. Video images of the renal microvessels were obtained using a CCD video camera (model ICD-42AC; Ikegami Tsushinki Co., Ltd., Tokyo, Japan) and recorded with a video cassette recorder (model EVO-9850; Sony Corp., Park Ridge, NJ). To determine the vessel diameter, the video recording was transmitted to an IBM-AT computer equipped with a display board (model TARGA+; Truevision Inc., Indianapolis, IN). Vessel diameters were estimated with an automated program custom-designed to determine the mean distance between parallel edges. The renal microvessel diameters were obtained during the plateau of the response. The segments of afferent arterioles near the parent interlobular artery and those of efferent arterioles near the glomerulus (23), $\sim 10 \mu \mathrm{m}$ in length, were scanned at 2-5-s intervals.

In the first series of experiments, the kidneys $(n=5)$ were exposed initially to increasing doses of AngII, from 0.03 to $0.3 \mathrm{nM}$ (11). In the presence of AngII $(0.3 \mathrm{nM})$, nifedipine $(1 \mu \mathrm{M})$ was administered to the perfusate (14). Finally, manganese was added directly to the media in a cumulative manner to achieve final concentrations of 4,8 , and $12 \mathrm{mM}$.

As shown in Fig. 1, the addition of AngII elicited prompt and sustained constriction in both afferent and efferent arterioles. Previous results showed that under our experimental conditions, AngII ( $0.3 \mathrm{nM})$ provoked renal microvascular constriction that persisted for a period of observation $>2 \mathrm{~h}(8)$. Thus, all the protocols using AngII were completed within $2 \mathrm{~h}$ after the administration of AngII.

In the second series of studies (four kidneys), AngII ( $0.3 \mathrm{nM})$ was

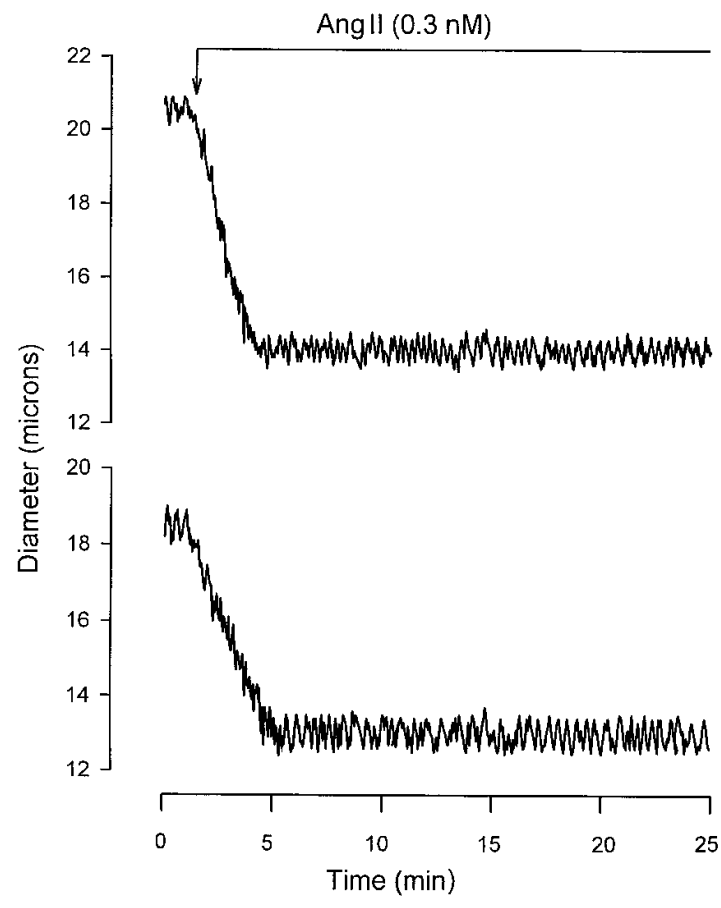

Figure 1. Representative tracings of afferent and efferent arteriolar responses to $0.3 \mathrm{nM}$ AngII. AngII elicited sustained afferent arteriolar constriction, from 20.4 to $14.1 \mu \mathrm{m}$ (top), within $5 \mathrm{~min}$. Similarly, AngII decreased efferent arteriolar diameter from 18.4 to $12.8 \mu \mathrm{m}$ (bottom).

administered first. Manganese was then added in a cumulative manner to obtain concentrations of 4,8 , and $12 \mathrm{mM}$.

In the third series of experiments, the kidneys $(n=4)$ were perfused with calcium-free medium for $10 \mathrm{~min}$. Calcium-free medium contained $2 \mathrm{mM}$ EGTA to decrease calcium concentration adequately (24). AngII (0.3 nM) was then administered (8).

In the fourth group, the influence of NEM on AngII-induced microvascular constriction was assessed (five kidneys). NEM, a sulfhydryl reagent, inhibits the Gi protein family (Go and Gi proteins) in the shortest time periods of the known $G$ protein antagonists (25). After basal arteriolar diameter was observed, NEM $(10 \mu \mathrm{M})$ was added. After a 30-min reequilibration period, AngII was administered to achieve final concentrations of 0.1 and $0.3 \mathrm{nM}$. Subsequently, manganese (4-8 $\mathrm{mM})$ was added.

In the fifth group, the kidneys $(n=4)$ were exposed to increasing doses of $\mathrm{NaF}(1-10 \mathrm{mM})$ in the presence of $\mathrm{AlCl}_{3}(10 \mu \mathrm{M})$, to activate $\mathrm{G}$ proteins directly (26). $\mathrm{Al} / \mathrm{NaF}$ is able to activate all $\mathrm{G}$ proteins by substituting for the terminal phosphate in the presence of GDP to mimic GTP (27). NCDC, an inhibitor of phospholipase C $(15,24)$, was then administered to the media in a cumulative manner (from 10 to $200 \mu \mathrm{M})$.

In the sixth series of studies, the kidneys $(n=5)$ were treated initially with $200 \mu \mathrm{M}$ NCDC. Our recent results demonstrated that this dose of NCDC arrested the increase in inositol trisphosphate production (24), suggesting efficient blockade of phospholipase $\mathrm{C}$ at the concentration used in this study. $30 \mathrm{~min}$ later, arteriolar responses to AngII (0.1-0.3 nM) were assessed. Subsequently, potassium concentration in the perfusate was increased isoosmotically to $30 \mathrm{meq} / \mathrm{liter}$ (14). Finally, manganese ( $4-8 \mathrm{mM})$ was administered.

In the seventh group, basal arteriolar diameter was observed first. The kidneys $(n=6)$ were then treated with thapsigargin $(1 \mu \mathrm{M})$, an inhibitor of endoplasmic reticulum Ca-ATPase (19). After a 30-min reequilibration period, AngII $(0.1-0.3 \mathrm{nM})$ was added in a cumulative manner. Finally, manganese $(8 \mathrm{mM})$ was administered. 
In the eighth group, the kidneys $(n=5)$ were treated with both $1 \mu \mathrm{M}$ of thapsigargin and $50 \mathrm{nM}$ of staurosporine, a protein kinase $\mathrm{C}$ inhibitor (28). We showed previously that under our experimental conditions, $50 \mathrm{nM}$ of staurosporine prevented endothelin-induced activation of protein kinase C (8). Increasing doses of AngII (0.1-0.3 nM) were then added. Subsequently, potassium concentration in the perfusate was increased to $30 \mathrm{meq} / \mathrm{liter}$ (14).

In the ninth series of studies, the kidneys $(n=5)$ were exposed to staurosporine $(50 \mathrm{nM})$ for $30 \mathrm{~min}$. AngII $(0.1-0.3 \mathrm{nM})$ was then administered to the perfusate.

Data are expressed as means \pm SE. Statistical significance was determined by Student's $t$ tests, or ANOVA followed by the NewmannKeuls test. $P$ values $<0.05$ were considered statistically significant.

\section{Results}

Fig. 2 illustrates the effects of nifedipine and manganese on AngII-induced microvascular constriction. The addition of 0.1 $\mathrm{nM}$ AngII constricted afferent arterioles by $14 \pm 2 \%$ (from $20.6 \pm 1.0$ to $17.8 \pm 0.8 \mu \mathrm{m}, n=8, P<0.01)$ and efferent arterioles by $10 \pm 2 \%$ (from $18.6 \pm 0.7$ to $16.8 \pm 0.5 \mu \mathrm{m}, n=8, P<$ $0.01)$, respectively. Increasing doses of AngII induced further renal microvascular constriction. At $0.3 \mathrm{nM}$, AngII reduced afferent arteriolar diameter by $29 \pm 3 \%$ (to $14.6 \pm 0.6 \mu \mathrm{m}, P<$ $0.01)$. AngII $(0.3 \mathrm{nM})$ constricted the efferent arteriole by $27 \pm 3 \%$ (to $13.6 \pm 0.8 \mu \mathrm{m}, P<0.01$ ). Subsequently, the effects of nifedipine $(1 \mu \mathrm{M})$ were examined. This dose of nifedipine was required to completely reverse afferent arteriolar constriction by KCl-induced membrane depolarization (14). Although the addition of nifedipine restored the decrements in AngIIinduced afferent arteriolar diameter (to $20.2 \pm 0.9 \mu \mathrm{m}$, not significant (NS) vs. control), it failed to alter efferent arteriolar diameter $(13.8 \pm 0.8 \mu \mathrm{m})$. Although the addition of increasing doses of manganese did not induce further alterations in afferent arteriolar diameter, it reversed AngII-induced efferent arteriolar constriction. At $4 \mathrm{mM}$, the addition of manganese reversed considerably AngII-induced efferent arteriolar constriction (to $15.1 \pm 0.7 \mu \mathrm{m}, P<0.05$ vs. $0.3 \mathrm{nM}$ AngII). Increasing the dose of manganese to $8 \mathrm{mM}$ elicited further efferent arteriolar dilation (to $16.9 \pm 0.7 \mu \mathrm{m}, P<0.01$ vs. $0.3 \mathrm{nM}$ AngII). However, $12 \mathrm{mM}$ of manganese failed to induce further efferent arteriolar dilation $(16.9 \pm 0.8 \mu \mathrm{m})$.

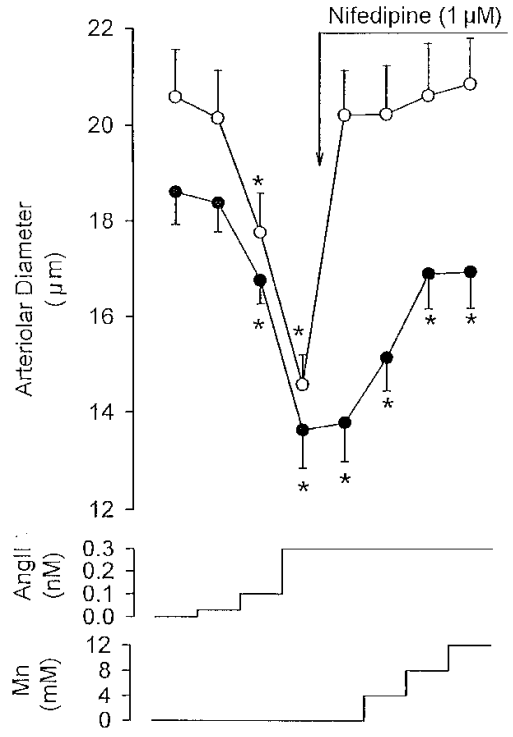

Figure 2. The effects of nifedipine and manganese $(M n)$ on AngIIinduced arteriolar constriction. Open and filled circles, afferent and efferent arterioles, respectively. *Significance, from the respective basal value.

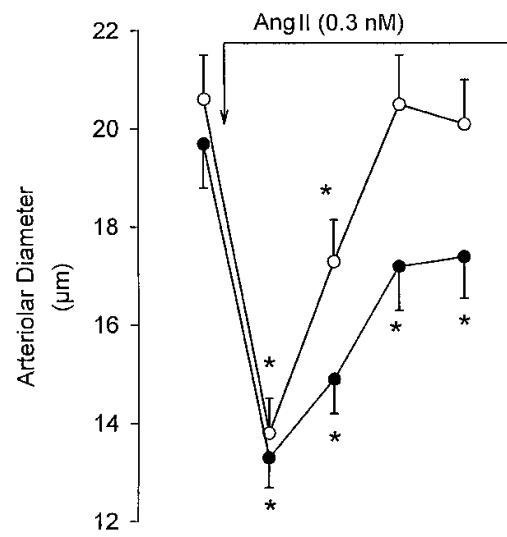

Figure 3. Influence of manganese $(\mathrm{Mn})$ on AngII-induced arteriolar constriction. Open and filled circles, afferent and efferent arterioles, respectively. *Significance, from the respective basal value.

Fig. 3 represents the influence of manganese on AngIIinduced renal vasoconstriction. AngII $(0.3 \mathrm{nM})$ constricted afferent and efferent arterioles by $27 \pm 3 \%$ (from $20.6 \pm 0.9$ to $13.8 \pm 0.7 \mu \mathrm{m}, n=6, P<0.01$ ) and $30 \pm 3 \%$ (from $19.7 \pm 0.9$ to $13.3 \pm 0.6 \mu \mathrm{m}, n=6, P<0.01$ ), respectively. Subsequent addition of manganese reversed AngII-induced microvascular constriction in a dose-dependent manner. At $4 \mathrm{mM}$, manganese reversed afferent (to $17.3 \pm 0.9 \mu \mathrm{m}, P<0.01 \mathrm{vs}$. AngII) and efferent arteriolar constriction (to $14.9 \pm 0.7 \mu \mathrm{m}, P<0.05$ vs. AngII). Manganese ( $8 \mathrm{mM})$ restored completely afferent arteriolar constriction (to $20.5 \pm 1.0 \mu \mathrm{m}$, NS vs. control), indicating that calcium entry mediates sustained afferent arteriolar con-

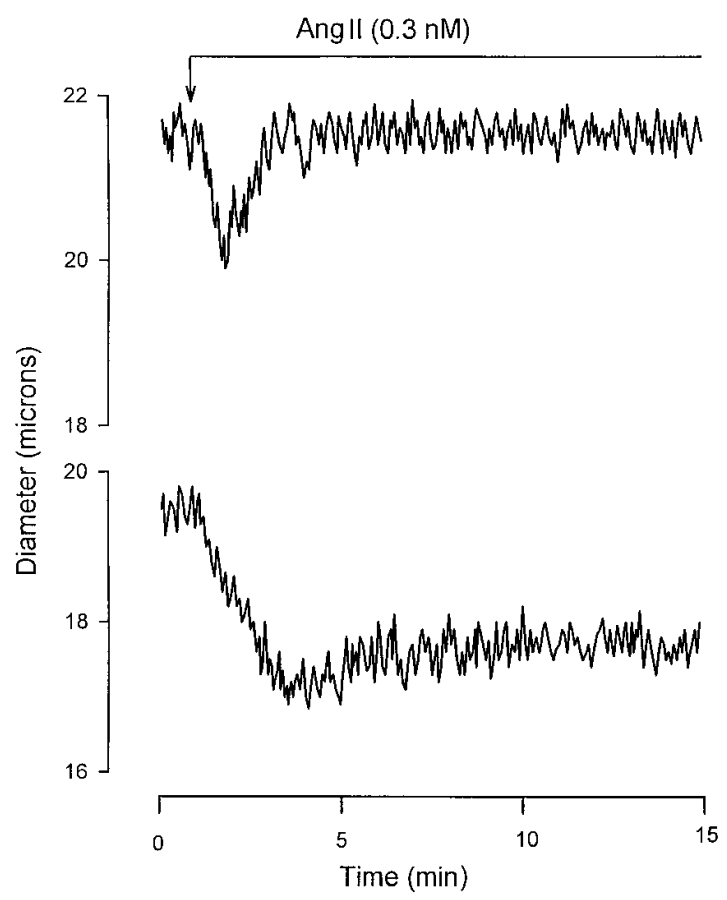

Figure 4. Representative tracings of arteriolar responses to $0.3 \mathrm{nM}$ AngII in calcium-free medium. AngII elicited only transient afferent arteriolar constriction, from 21.6 to $19.9 \mu \mathrm{m}($ top $)$. In contrast, the efferent arteriole manifested persistent constriction, from 19.5 to $17.7 \mu \mathrm{m}$, by AngII (bottom). 
striction by AngII, but it reversed only partially efferent arteriolar constriction (to $17.2 \pm 0.9 \mu \mathrm{m}, P<0.05$ vs. control). Increasing manganese to $12 \mathrm{mM}$ failed to induce further alterations in either afferent or efferent arteriolar diameters.

As shown in Fig. 4, in calcium-free medium, the addition of AngII $(0.3 \mathrm{nM})$ elicited transient afferent arteriolar constriction, providing evidence that calcium mobilization occurred by AngII. However, sustained afferent arteriolar constriction by AngII was abolished (from $22.0 \pm 1.1$ to $21.9 \pm 1.0 \mu \mathrm{m}, n=6$ ). When the kidneys were exposed to calcium-free medium, AngII $(0.3 \mathrm{nM})$ produced a sustained decrease in efferent arteriolar diameter of $1.7 \pm 0.3 \mu \mathrm{m}(P<0.05$ vs. zero, $n=6)$ at 10 min after its administration. Nevertheless, the magnitude of AngII-induced efferent arteriolar constriction in calcium-free medium was attenuated compared with normal medium $(P<$ 0.01). Thus, in calcium-free medium, $0.3 \mathrm{nM}$ AngII constricted efferent arterioles by $7 \pm 2 \%$ (from $18.7 \pm 0.9$ to $17.1 \pm 0.7 \mu \mathrm{m}, n=$ $6)$, which is identical to the magnitude of AngII (0.3 nM)induced efferent arteriolar constriction $(9 \pm 2 \%)$ in the presence of manganese $(8 \mathrm{mM})$, supporting the actions of manganese as a calcium entry blocker.

Fig. 5 depicts the effect of NEM, a blocker of the Gi protein family, on AngII-induced renal microvascular constriction. Treatment with NEM did not elicit any changes in afferent (from $19.5 \pm 0.6$ to $19.4 \pm 0.6 \mu \mathrm{m}, n=6$ ) or efferent arteriolar diameter (from $18.5 \pm 0.6$ to $18.6 \pm 0.7 \mu \mathrm{m}, n=6$ ). Subsequent addition of AngII constricted afferent arterioles by $20 \pm 2$ (to $15.5 \pm 0.4 \mu \mathrm{m}, P<0.01$ ) and $34 \pm 3 \%$ (to $13.1 \pm 0.4$ $\mu \mathrm{m}, P<0.01)$ at 0.1 and $0.3 \mathrm{nM}$, respectively. Treatment with NEM blocked efferent arteriolar constriction. In the presence of NEM, AngII up to $0.3 \mathrm{nM}$ did not alter efferent arteriolar diameter $(18.5 \pm 0.8 \mu \mathrm{m})$. Administration of increasing concentrations of manganese failed to alter efferent arteriolar diameter. However, the addition of $4 \mathrm{mM}$ of manganese reversed partially AngII-induced afferent arteriolar constriction, to $16.7 \pm 0.5 \mu \mathrm{m}(P<0.01$ vs. $0.3 \mathrm{nM}$ AngII $)$. At $8 \mathrm{mM}$, manganese returned afferent arteriolar diameter to $19.7 \pm 0.5 \mu \mathrm{m}$ (NS vs. control).

Fig. 6 exhibits the effect of NCDC, a phospholipase C inhibitor, on $\mathrm{NaF}$-induced renal microvascular constriction. Al-

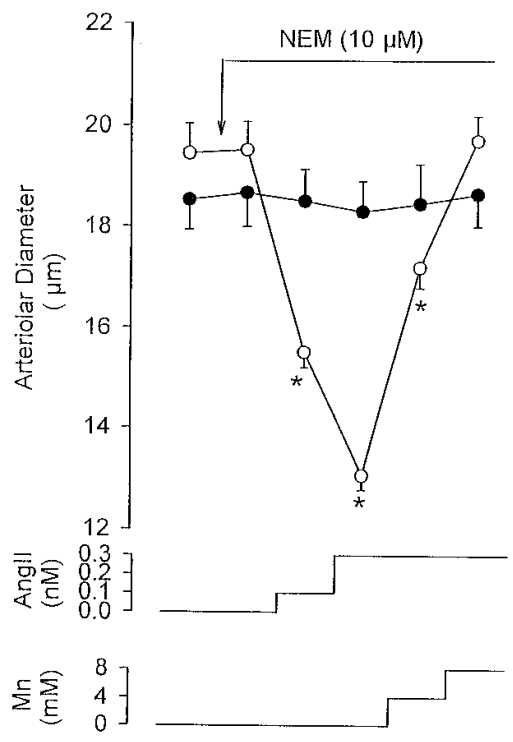

Figure 5. Impact of NEM $(10 \mu \mathrm{M})$ on AngII-induced arteriolar constriction. Open and filled circles, afferent and efferent arterioles, respectively. $M n$, manganese. *Significance, from basal value.

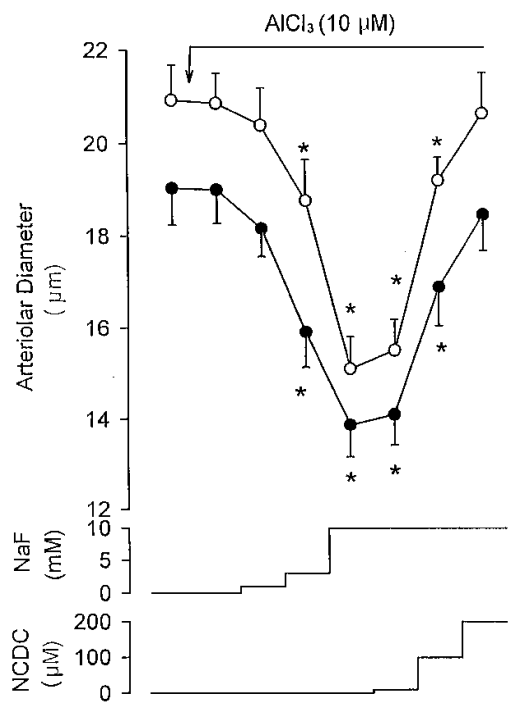

Figure 6. Effect of NCDC on NaF-induced arteriolar constriction. Open and filled circles, afferent and efferent arterioles, respectively. *Significance, from the respective basal value. though the addition of $\mathrm{AlCl}_{3}$ altered neither afferent (from $20.9 \pm 0.8$ to $20.9 \pm 0.6 \mu \mathrm{m}, n=6$ ) nor efferent arteriolar diameter (from $19.0 \pm 0.8$ to $19.0 \pm 0.7 \mu \mathrm{m}, n=6$ ), subsequent exposure to $\mathrm{NaF}$ elicited both afferent and efferent arteriolar constriction. At $3 \mathrm{mM}, \mathrm{NaF}$ decreased afferent arteriolar diameter by $11 \pm 1 \%$ (to $18.8 \pm 0.9 \mu \mathrm{m}, P<0.05$ ) and reduced efferent arteriolar diameter by $16 \pm 2 \%$ (to $15.9 \pm 0.8 \mu \mathrm{m}, P<0.05$ ). At $10 \mathrm{mM}, \mathrm{NaF}$ provoked further afferent and efferent arteriolar constriction, to $15.1 \pm 0.7$ and $13.9 \pm 0.7 \mu \mathrm{m}$, respectively. NCDC reversed $\mathrm{NaF}$-induced arteriolar constriction in a dose-dependent manner. At $100 \mu \mathrm{M}$, NCDC reversed afferent and efferent arteriolar constriction by $\mathrm{NaF}$ to $19.0 \pm 0.5$ and $16.6 \pm 0.8 \mu \mathrm{m}$ $(P<0.05$ vs. $10 \mathrm{mM} \mathrm{NaF}$ for both $)$, respectively. At $200 \mu \mathrm{M}$, NCDC restored completely $\mathrm{NaF}$-induced decrements in both afferent (to $20.7 \pm 0.9 \mu \mathrm{m}$, NS vs. control) and efferent (to $18.5 \pm 0.8 \mu \mathrm{m}$, NS vs. control) arteriolar diameter, indicating that under our experimental conditions, this dose of NCDC was required to inhibit phospholipase $\mathrm{C}$ activated via $\mathrm{G}$ proteins.

Fig. 7 summarizes the effect of NCDC on AngII-induced renal microvascular constriction. The addition of NCDC $(200$ $\mu \mathrm{M}$ ) did not alter either afferent (from $20.0 \pm 1.0$ to $19.7 \pm 1.0$ $\mu \mathrm{m}, n=6$ ) or efferent arteriolar diameter (from 18.5 \pm 0.9 to $18.6 \pm 0.8 \mu \mathrm{m}, n=6$ ). However, subsequent addition of AngII up to $0.3 \mathrm{nM}$ failed to elicit both afferent $(19.5 \pm 1.1 \mu \mathrm{m})$ and efferent arteriolar constriction $(18.2 \pm 1.0 \mu \mathrm{m})$. Increasing potassium concentration (from $4 \pm 1$ to $30 \pm 3 \mathrm{meq} / \mathrm{liter}, n=5, P<$ 0.01 ) constricted afferent arterioles by $30 \pm 4 \%$ (to $13.8 \pm 0.8 \mu \mathrm{m}$, $P<0.01$ ), but it did not alter efferent arteriolar diameter $(17.9 \pm 0.9 \mu \mathrm{m})$. Although subsequent administration of manganese did not induce any changes in efferent arteriolar diameter, it reversed afferent arteriolar constriction in a dose-dependent manner. At $4 \mathrm{mM}$, manganese dilated afferent arterioles to $17.4 \pm 0.9 \mu \mathrm{m}(P<0.05 \mathrm{vs}$. $\mathrm{KCl})$. Increasing manganese concentration to $8 \mathrm{mM}$ returned afferent arteriolar diameter to $19.9 \pm 1.1 \mu \mathrm{m}$ (NS vs. control).

Fig. 8 describes the effect of thapsigargin, an endoplasmic reticulum calcium pump inhibitor, on AngII-induced renal vasoconstriction. The addition of thapsigargin $(1 \mu \mathrm{M})$ failed to alter both afferent (from 21.1 \pm 0.9 to $21.7 \pm 0.9 \mu \mathrm{m}, n=8$ ) and efferent arteriolar diameter (from 19.4 \pm 0.8 to $19.8 \pm 0.9 \mu \mathrm{m}$, 


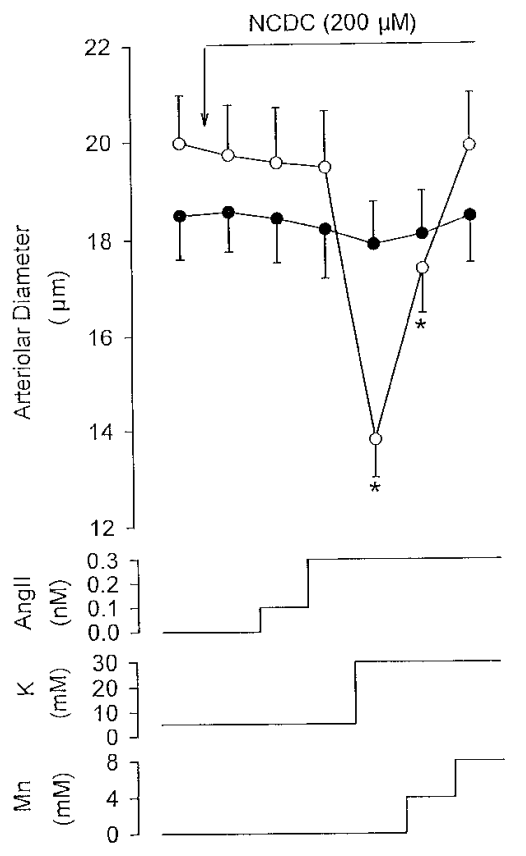

Figure 7. Influence of NCDC $(200 \mu \mathrm{M})$ on AngII-induced arteriolar constriction. Open and filled circles, afferent and efferent arterioles, respectively. $*$ Significance, from basal value.

$n=8)$. However, subsequent addition of AngII (0.1-0.3 nM) elicited neither phasic nor sustained afferent arteriolar constriction $(21.3 \pm 0.8 \mu \mathrm{m})$. Treatment with thapsigargin attenuated AngII-induced efferent arteriolar constriction. In the presence of thapsigargin, AngII $(0.3 \mathrm{nM})$ decreased efferent arteriolar diameter by $8 \pm 2 \%$ (to $17.7 \pm 0.6 \mu \mathrm{m}, P<0.05$ ). Although subsequent administration of manganese $(8 \mathrm{mM})$ did not induce further alterations in afferent arteriolar diameter, it reversed completely efferent arteriolar constriction, to $19.4 \pm$ $0.8 \mu \mathrm{m}$ (NS vs. control).

Fig. 9 displays the influence of staurosporine $(50 \mathrm{nM})$ and thapsigargin $(1 \mu \mathrm{M})$ on AngII-induced microvascular constriction. Treatment with staurosporine did not alter either afferent (from $23.5 \pm 1.2$ to $23.7 \pm 1.1 \mu \mathrm{m}, n=6$ ) or efferent arteriolar diameter (from $20.5 \pm 1.0$ to $20.3 \pm 1.0 \mu \mathrm{m}, n=6$ ). Subsequent administration of thapsigargin $(1 \mu \mathrm{M})$ failed to induce changes

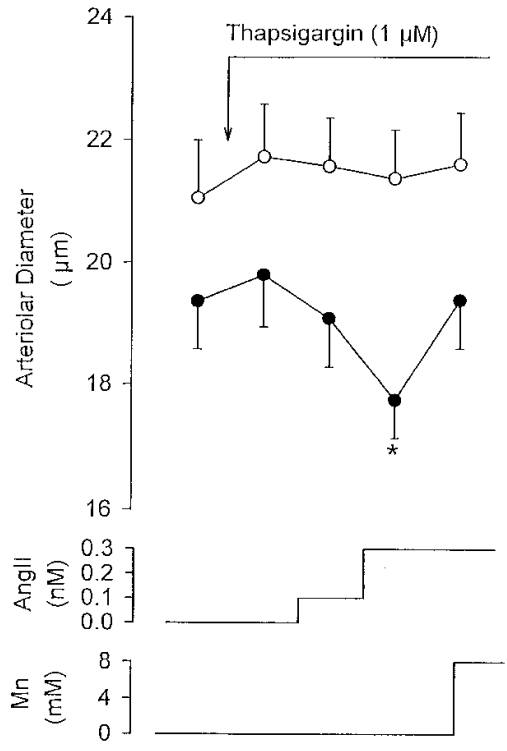

Figure 8. Effect of thapsigargin $(1 \mu \mathrm{M})$ on AngII-induced arteriolar constriction. Open and filled circles, afferent and efferent arterioles, respectively. $* P<$ 0.05 from the basal value.

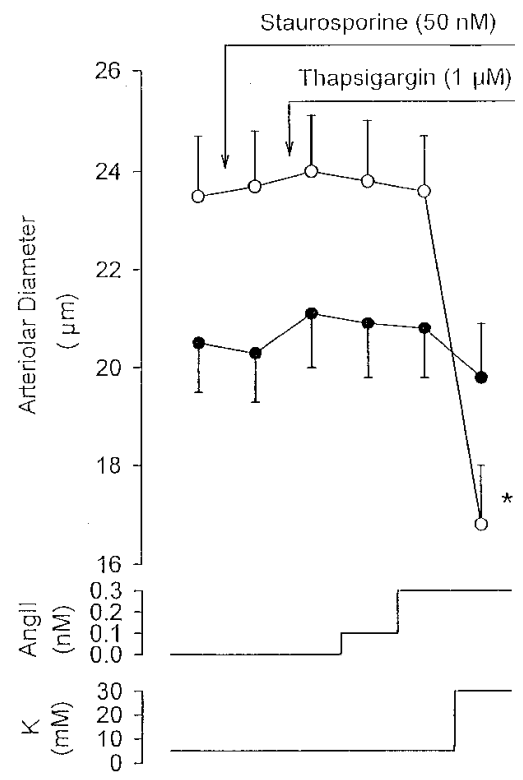

Figure 9. Impact of combined treatment with thapsigargin (1 $\mu \mathrm{M})$ and staurosporine (50 $\mathrm{nM})$ on AngIIinduced arteriolar constriction. Open and filled circles, afferent and efferent arterioles, respectively. ${ }^{*} P<0.01$ from the basal value.

in either afferent (to $24.0 \pm 1.1 \mu \mathrm{m}$ ) or efferent arteriolar diameter $(21.1 \pm 1.1 \mu \mathrm{m})$. Subsequent administration of AngII up to $0.3 \mathrm{nM}$ did not elicit either afferent (to $23.6 \pm 1.1 \mu \mathrm{m}$ ) or efferent arteriolar constriction (to $20.8 \pm 1.0 \mu \mathrm{m}$ ). However, increasing potassium concentrations in the perfusate (from $5 \pm 1$ to 29 $\pm 3 \mathrm{meq} / \mathrm{liter}, n=5, P<0.01)$ constricted afferent arterioles to $16.8 \pm 1.2 \mu \mathrm{m}(P<0.01)$ in the presence of both thapsigargin and staurosporine. These findings suggest that neither thapsigargin nor staurosporine influences calcium channels or myosin light chain kinase at the concentrations used in this study, providing evidence for the specificity of these blockers.

Fig. 10 delineates the impact of staurosporine on AngIIinduced microvascular constriction. Although the addition of staurosporine itself failed to alter both afferent (from 18.2 \pm 1.9 to $18.2 \pm 1.8 \mu \mathrm{m}, n=8$ ) and efferent arteriolar diameter (from $16.2 \pm 1.9$ to $16.3 \pm 1.9 \mu \mathrm{m}, n=8$ ), it attenuated AngII-induced efferent arteriolar constriction (at 0.1 and $0.3 \mathrm{nM}$ of AngII, $P<0.05$ vs. untreated). Thus, at $0.3 \mathrm{nM}$, AngII elicited modest efferent arteriolar constriction in the presence of staurosporine, by $13 \pm 3 \%$ (to $13.8 \pm 1.5 \mu \mathrm{m}, P<0.05$ vs. control). In con-

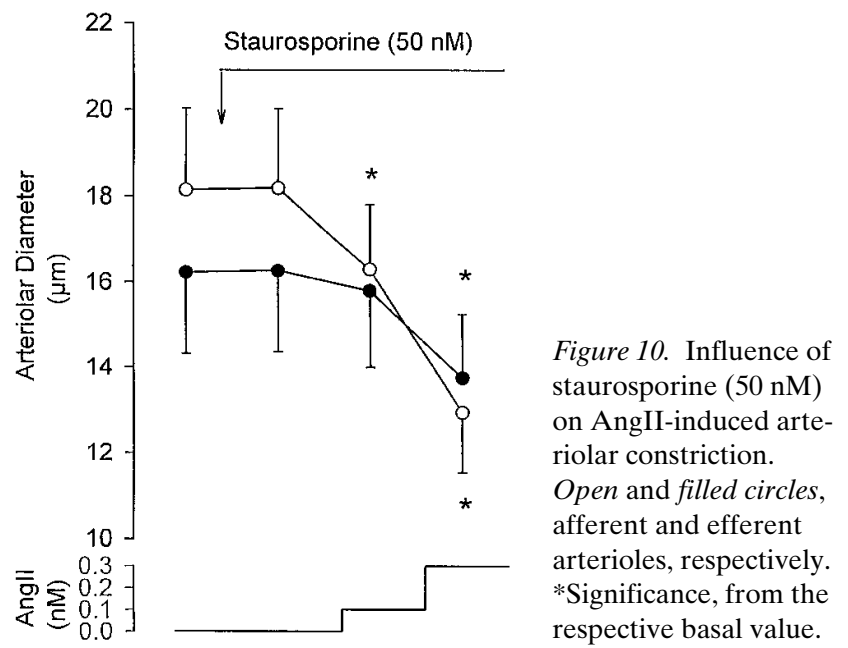


trast, AngII-induced afferent arteriolar constriction was not altered significantly by the inhibition of protein kinase C. AngII $(0.3 \mathrm{nM})$ decreased afferent arteriolar diameter by $28 \pm 3 \%$ (to $13.0 \pm 1.4 \mu \mathrm{m}, P<0.01$ vs. control) in the presence of staurosporine.

\section{Discussion}

Signal transduction mediating vascular effects of AngII has been investigated extensively, using isolated vascular stripe and cultured vascular smooth muscle cells. Although most of the physiological responses to AngII are mediated by $\mathrm{AT}_{1}$ receptors (29), the postreceptor mechanisms appear to differ among various vascular beds. Recent studies indicate that AngII transduces its signal with second messengers synthesized by phospholipase C in arterial smooth muscle (29). However, Ohya and Sperelakis (30) have demonstrated that AngII gates calcium channels by coupling with $\mathrm{G}$ protein in the portal vein. Thus, cellular mechanisms mediating AngII-induced renal microvascular constriction may differ from those in large vessels. Furthermore, the postreceptor processes involved in contractile responses to AngII may vary among distinct segments of renal microvascular beds.

AngII $\mathrm{AT}_{1}$ receptors are coupled with phospholipase $\mathrm{C}$ in aortic vascular smooth muscle (29). We showed previously that losartan reversed afferent arteriolar constriction by AngII (31), indicating the presence of $\mathrm{AT}_{1}$ receptors on this vessel. In isolated renal microvessels, the addition of AngII increases inositol trisphosphate levels (32), suggesting that, as in large vessels, $\mathrm{AT}_{1}$ receptors are coupled with phospholipase $\mathrm{C}$ in renal microvasculature. In agreement with this finding, these results have demonstrated that NCDC, a phospholipase $\mathrm{C}$ inhibitor, blocked afferent arteriolar constriction by AngII. Although G proteins transduce signals from $\mathrm{AT}_{1}$ receptors to phospholipase $\mathrm{C}(29,33)$, NEM failed to modify afferent arteriolar constriction by AngII. However, our observations that $\mathrm{NaF}$-induced afferent arteriolar constriction was reversed by NCDC suggest a linkage between $\mathrm{G}$ protein and phospholipase $\mathrm{C}$ in this vessel. Because phospholipase $\mathrm{C}$ couples with $\mathrm{Gq}$ or $\mathrm{Gi}$ protein families (34), and because NEM exhibits pharmacological actions similar to pertussis toxin in inhibiting the Gi protein family (25), these findings suggest that $\mathrm{AT}_{1}$ receptors on afferent arterioles are coupled with phospholipase $\mathrm{C}$ presumably via NEM-insensitive $\mathrm{G}(\mathrm{q})$ proteins.

Our data revealed that manganese or nifedipine restored decrements in afferent arteriolar diameter by AngII. As discussed previously $(7,8)$, these data indicate a mediatory role of calcium entry through L-type calcium channels in sustained afferent arteriolar constriction by AngII. Furthermore, we have demonstrated that treatment with NCDC or thapsigargin prevented afferent arteriolar constriction by AngII. Collectively, our findings suggest that in afferent arterioles, phospholipase $\mathrm{C}$-dependent calcium release from endoplasmic reticulum (35) triggers subsequent cellular responses that activate voltage-dependent calcium channels. Electrophysiological studies indicate the presence of calcium-activated chloride channels on preglomerular vessels, including afferent arterioles $(10,36)$. Furthermore, previous data demonstrated that chloride channel blockade inhibited AngII-induced afferent arteriolar constriction $(11,37)$. Thus, these observations support the recent proposal that AngII-induced intracellular calcium mobilization renders chloride channels on the afferent arteriole more likely to open, thereby eliciting membrane depolarization and consequent activation of voltage-dependent calcium channels.

Although efferent arteriolar constriction by AngII is mediated by $\mathrm{AT}_{1}$ receptors (31), the postreceptor mechanisms appear to differ from those of afferent arterioles. Ruan and Arendshorst (38) reported that cotreatment with nifedipine and 8-( $N, N$-diethylamino)-octyl-3,4,5-trimethoxybenzoate diminished but did not prevent renal vasoconstriction by AngII. In accordance, we have shown that pretreatment with thapsigargin attenuated but did not block AngII-induced efferent arteriolar constriction. Furthermore, these data indicate that the coadministration of manganese with thapsigargin abolished efferent arteriolar constriction by AngII. Thus, our data indicate that both calcium mobilization and calcium entry are required for full expression of sustained AngII-induced efferent arteriolar constriction. However, it is unlikely that capacitive calcium current accounts for this calcium entry, because thapsigargin itself, which strongly recruits capacitive calcium entry (39), failed to induce vasoconstriction. Alternatively, recent studies indicate that AngII induces calcium entry by opening receptor-operated calcium-permeable channels via a phospholipase C-dependent process in vascular smooth muscle (15). In addition, we have shown that AngII does not elicit efferent arteriolar constriction in the presence of either NEM or NCDC. Collectively, our results are consistent with those of Pfeilschifter and Bauer (40), that pertussis toxin blocked the stimulation of phospholipase $\mathrm{C}$ by AngII in mesangial cells, and suggest further that in the efferent arteriole, the activation of $\mathrm{AT}_{1}$ receptors triggers phospholipase $\mathrm{C}$ through NEM-sensitive $\mathrm{G}(\mathrm{i})$ proteins, thereby eliciting not only calcium mobilization but also calcium entry.

Our results are compatible with the observations of Ichikawa et al. (12). Using micropuncture methods, they demonstrated that manganese reversed AngII-induced increase in efferent arteriolar resistance. However, our findings differed from those of Conger et al. (13) showing that efferent arteriolar constriction was mediated by calcium mobilization. Although the reasons for observed differences are not readily apparent, they may relate to the temporal profile of constriction. While Conger et al. (13) observed efferent arteriolar diameter for $4 \mathrm{~min}$ after the addition of AngII, we examined AngII-induced efferent arteriolar constriction at least $10 \mathrm{~min}$ after AngII administration. Taken together, these results suggest that calcium entry participates considerably in sustained efferent arteriolar constriction by AngII.

Our findings may provide insight into the signal transduction pathway that allows calcium entry in efferent arterioles. Previous data using various methods imply that voltagedependent calcium channels are lacking in the efferent arteriole $(14,41,42)$. Consistent with this, our recent results indicated that isradipine $(0.1 \mu \mathrm{M})$, a calcium antagonist, reversed AngII-induced afferent but not efferent arteriolar constriction (8). In this study, we showed that nifedipine did not alter efferent arteriolar constriction by AngII. Furthermore, in the presence of NCDC, AngII did not elicit efferent arteriolar constriction. Our data are compatible with those of Ruegg et al. (15), and indicate a mediatory role for phospholipase C in AngIIinduced calcium influx into efferent arterioles. Indeed, recent investigations reveal that the products of phospholipase $\mathrm{C}$ regulate voltage-independent calcium-permeable cation channels (43). On the one hand, inositol tris- and/or tetrakis-phosphate activates calcium entry (39). On the other hand, protein kinase 
C opens calcium-permeable cation channels (44). We have demonstrated that cotreatment with thapsigargin and staurosporine abolished efferent arteriolar constriction by AngII. Our findings are thus consistent with the latter finding, and provide evidence that protein kinase C is involved in AngIIinduced calcium entry into efferent arterioles. This notion is supported by the observation that staurosporine itself attenuated efferent arteriolar constriction by AngII. These results suggest that in efferent arterioles, AngII-induced activation of protein kinase $\mathrm{C}$ gates voltage-independent calcium-permeable channels.

Although precise reasons for preferential action of protein kinase $\mathrm{C}$ in efferent arterioles are not readily apparent, they may relate to the difference in G proteins involved in AngII signaling in afferent and efferent arterioles. Marked stimulation of phospholipase $\mathrm{C}$ and/or inhibition of adenylate cyclase would favor significant action of protein kinase $\mathrm{C}(18,34)$. Further studies using freshly isolated glomerular arteriolar myocytes are required to elucidate a definite molecular basis in this issue.

Finally, a caveat should be considered. AngII enhances tubuloglomerular feedback (TGF), contributing to glomerular arteriolar constriction by this peptide $(45,46)$. The mechanisms underlying TGF may overlap with those mediating AngIIinduced renal constriction in vivo. However, in our in vitro model, TGF is not operating efficiently due to tubular atrophy (11). Thus, the action of TGF would not confound the interpretation of our results. Collectively, these findings suggest that arteriolar behavior towards AngII observed in this study represents direct action of this peptide on renal microvasculature.

In summary, these findings indicate that AngII constricts considerably both afferent and efferent arterioles. Furthermore, our results suggest that in afferent arterioles, the activation of $\mathrm{AT}_{1}$ receptors by AngII stimulates phospholipase $\mathrm{C}$ with subsequent calcium mobilization that gates chloride channels, thereby inducing membrane depolarization and activation of voltage-dependent calcium channels. Finally, our data provide the first evidence that in efferent arterioles, $\mathrm{AT}_{1}$ receptors are coupled with NEM-sensitive G proteins that trigger phospholipase $\mathrm{C}$, thereby eliciting both calcium mobilization and calcium entry.

\section{Acknowledgments}

The authors thank Keita Suzuki for excellent care of animals and Bayer Co. Ltd. for supplying nifedipine.

This study was supported in part by a grant from the Ministry of Health and Welfare, Japan.

\section{References}

1. Blantz, R.C., K.S. Konnen, and B.J. Tucker. 1976. Angiotensin II effects upon the glomerular microcirculation and ultrafiltration coefficient of the rat. $J$. Clin. Invest. 57:419-434.

2. Ichikawa, I., and R.C. Harris. 1991. Angiotensin action in the kidney; renewed insight into the old hormone. Kidney Int. 40:583-596.

3. Dzau, V.J., W.S. Colucci, G.H. Williams, G. Curfman, L. Meggs, and N.K. Hollenberg. 1980. Sustained effectiveness of converting enzyme inhibition in patients with severe congestive heart failure. N. Engl. J. Med. 302:1373-1379.

4. Takenaka, T., H. Suzuki, T. Furukawa, Y. Ogata, and T. Saruta. 1990. Role of intrarenal renin-angiotensin system on pressure-natriuresis in spontaneously hypertensive rats. Clin. Exp. Hypertens. A12:1377-1394.

5. Lu, S., D.L. Mattson, and A.W. Cowley. 1994. Renal medullary captopril delivery lowers blood pressure in spontaneously hypertensive rats. Hyperten- sion. 23:337-345.

6. Anderson, S., H.G. Rennke, and B.M. Brenner. 1986. Therapeutic advantage of converting enzyme inhibitors in arresting progressive renal disease associated with systemic hypertension in the rat. J. Clin. Invest. 77:1933-2000.

7. Carmines, P.K., and L.G. Navar. 1989. Disparate effects of Ca channel blockade on afferent and efferent arteriolar responses to ANG II. Am. J. Physiol. 256:F1015-F1020.

8. Takenaka, T., H. Forster, and M. Epstein. 1993. Protein kinase C and calcium channel activation as determinants of renal vasoconstriction by angiotensin II and endothelin. Circ. Res. 73:743-750.

9. Ito, S., C.S. Johnson, and O.A. Carretero. 1991. Modulation of angiotensin II-induced vasoconstriction by endothelium-derived relaxing factor in the isolated perfused rabbit afferent arteriole. J. Clin. Invest. 87:1656-1663.

10. Kurtz, A., and R. Penner. 1990. Effects of angiotensin II on intracellular calcium and electrical function of mouse renal juxtaglomerular cells. Kidney Int. Suppl. 30:S51-S54.

11. Takenaka, T., Y. Kanno, Y. Kitamura, K. Hayashi, H. Suzuki, and T. Saruta. 1996. Role of chloride channels in afferent arteriolar constriction. Kidney Int. 50:864-872.

12. Ichikawa, I., J.F. Miele, and B.M. Brenner. 1979. Reversal of renal cortical actions of angiotensin II by verapamil and manganese. Kidney Int. 16:137147

13. Conger, J.D., S.A. Falk, and J.B. Robinette. 1993. Angiotensin II-induced changes in smooth muscle calcium in rat renal arterioles. J. Am. Soc. Nephrol. 3 . 1792-1803.

14. Loutzenhiser, R., K. Hayashi, and M. Epstein. 1989. Divergent effects of $\mathrm{KCl}$-induced depolarization on afferent and efferent arterioles. Am. J. Physiol. 257:F561-F564.

15. Ruegg, U.T., A. Wallnofer, S. Weir, and C. Cauvin. 1989. Receptoroperated calcium-permeable channels in vascular smooth muscle. J. Cardiovasc. Pharmacol. 14(Suppl. 6):S49-S58.

16. Van Renterghem, C., and M. Lazdunski. 1994. Identification of the $\mathrm{Ca}^{2+}$ current activated by vasoconstrictors in vascular smooth muscle cells. Pflugers Arch. 429:1-6.

17. Takenaka, T., and H. Forster. 1997. Arginine vasopressin interacts with thromboxane in hydronephrosis. Am. J. Physiol. 272:F40-F47.

18. Jakobs, K.H., P. Lasch, M. Minuth, K. Aktories, and G. Schultz. 1985. Uncoupling of $\alpha$-adrenoceptor-mediated inhibition of human platelet adenylate cyclase by $N$-ethylmaleimide. J. Biol. Chem. 257:2829-2833.

19. Thastrup, O., P.J. Cullen, B.K. Drobak, M.R. Hanley, and A.P. Dawson. 1990. Thapsigargin, a tumor promoter, discharges intracellular Ca store by specific inhibition of the endoplasmic reticulum Ca-ATPase. Proc. Natl. Acad. Sci. USA. 87:2466-2470.

20. Steinhausen, M., H. Sonei, N. Parekh, R. Baker, and P.C. Johnson. 1983. Hydronephrosis: a new method to visualize vas afferens, efferens and glomerular network. Kidney Int. 23:794-806.

21. Loutzenhiser, R., K. Hayashi, and M. Epstein. 1988. Atrial natriuretic peptide reverses afferent arteriolar vasoconstriction and potentiates efferent arteriolar vasoconstriction in the isolated perfused kidney. J. Pharmacol. Exp. Ther. 246:522-528.

22. Takenaka, T., Y. Hashimoto, and M. Epstein. 1992. Diminished acetylcholine-induced vasodilation in renal microvessels of cyclosporine-treated rats. J. Am. Soc. Nephrol. 3:42-50.

23. Takenaka, T., H. Forster, and M. Epstein. 1993. Characterization of the renal microvascular actions of a new dopaminergic agonist, YM435. J. Pharmacol. Exp. Ther. 264:1154-1159.

24. Hishikawa, K., T. Nakaki, T. Marumo, M. Hayashi, H. Suzuki, R. Kato, and T. Saruta. 1994. Pressure promotes DNA synthesis in rat cultured vascular smooth muscle cells. J. Clin. Invest. 93:1975-1980.

25. Liebau, S., J. Hohlfeld, and U. Forstermann. 1989. The inhibition of $\alpha$-adrenoceptor-mediated contractions of rabbit pulmonary artery by Ca-withdrawal, pertussis toxin and $N$-ethylmaleimide is dependent on agonist intrinsic efficacy. Naunyn-Schmiedeberg's Arch. Pharmacol. 339:496-502.

26. Weber, L.P., W.L. Chow, W. Abebe, and K.M. MacLeod. 1996. Enhanced contractile responses of arteries from streptozotocin diabetic rats to sodium fluoride. Br. J. Pharmacol. 118:115-122.

27. Bigay, J., P. Deyerre, C. Pfister, and M. Chabre. 1985. Fluoroaluminates activate transducin-GDP by mimicking the gamma-phosphate of GTP in its binding site. FEBS (Fed. Eur. Biochem. Soc.) Lett. 191:181-185.

28. Tamaoki, T., H. Nomoto, I. Takahashi, Y. Kato, M. Morimoto, and F. Tomita. 1986. Staurosporine, a potent inhibitor of phospholipid/Ca ${ }^{++}$dependent protein kinase. Biochem. Biophys. Res. Commun. 135:397-402.

29. Lassegue, G., K.K. Griendling, and R.W. Alexander. 1994. Molecular biology of angiotensin II receptors. In Angiotensin Receptors. J.M. Saavedra and P.B.M.W.M. Timmermans, editors. Plenum Publishing Corp., New York. $17-44$.

30. Ohya, Y., and N. Sperelakis. 1991. Involvement of a GTP-binding protein in stimulating actions of angiotensin II on calcium channels in vascular smooth muscle cells. Circ. Res. 68:767-771.

31. Loutzenhiser, R., M. Epstein, K. Hayashi, T. Takenaka, and H. Forster 1991. Characterization of the renal microvascular effects of angiotensin II antagonist, DuP 753: studies in isolated perfused hydronephrotic kidneys. Am. J. 
Hypertens. 4:309S-314S

32. McArdle, S., and P.K. Carmines. 1994. Agonist-induced stimulation of phosphoinositide hydrolysis in preglomerular microvessels from rat kidneys. $J$. Am. Soc. Nephrol. 5:586. (Abstr.)

33. De Gasparo, M., A. Husain, W. Alexander, K.J. Catt, A.T. Chiu, M. Drew, T. Goodfriend, J.W. Harding, T. Inagami, and P.B. Timmermans. 1995. Proposed update of angiotensin receptor nomenclature. Hypertension. 25:924927.

34. Birnbaumer, L., J. Abramowitz, and A.M. Brown. 1990. Receptor-effector coupling by G proteins. Biochim. Biophys. Acta. 1031:163-224.

35. Komori, S., and T.B. Bolton. 1991. Calcium release induced by inositol 1,4,5-trisphosphate in rabbit intestinal smooth muscle cells. J. Physiol. (Camb.). 433:495-517.

36. Gordienko, D.V., C. Clausen, and M.S. Goligorsky. 1994. Ionic currents and endothelin signaling in smooth muscle cells from rat renal resistance arteries. Am. J. Physiol. 266:F325-F341.

37. Jensen, B.L., and O. Skott. 1996. Blockade of chloride channels by DIDS stimulates renin release and inhibits contraction of afferent arterioles. Am. J. Physiol. 270:F718-F727.

38. Ruan, X., and W.J. Arendshorst. 1996. Calcium entry and mobilization signaling pathways in ANG II-induced renal vasoconstriction in vivo. Am. J. Physiol. 270:F398-F405.
39. Berridge, M.J. 1993. Inositol trisphosphate and calcium signalling. $\mathrm{Na}$ ture (Lond.). 361:315-325.

40. Pfeilschifter, J., and C. Bauer. 1986. Pertussis toxin abolishes angiotensin II-induced phosphoinositide hydrolysis and prostaglandin synthesis in rat renal mesangial cells. Biochem. J. 236:289-294.

41. Carmines, P.K., B.C. Fowler, and P.D. Bell. 1993. Segmentally distinct effects of depolarization on intracellular Ca in renal arterioles. Am. J. Physiol. 265:F677-F685.

42. Steinhausen, M., M. Baehr, and R. Dussel. 1989. Vasomotion and vasoconstriction induced by a Ca-agonist in the split hydronephrotic kidney. Prog. Appl. Microvasc. 14:25-39.

43. Schultz, G., W. Rosenthal, J. Hescheler, and W. Trautwein. 1990. Role of G protein in calcium channel modulation. Annu. Rev. Physiol. 52:275-292.

44. Oike, M., K. Kitayama, and H. Kuriyama. 1993. Protein kinase C activates the non-selective cation channel in the rabbit portal vein. Pflugers Arch. 424:159-164.

45. Ikenaga, H., R.W. Fallet, and P.K. Carmines. 1996. Contribution of tubuloglomerular feedback to renal arteriolar angiotensin II responsiveness. Kidney Int. 49:34-39.

46. Schnermann, J., and J. Briggs. 1986. Role of renin-angiotensin system in tubuloglomerular feedback. Fed. Proc. 45:1426-1430. 